\title{
The Impact of Targeted Education of American Urological Association Cryptorchidism Guidelines in a Rural State: Improvement Still Needed
}

\author{
Tyler Trump' \\ Amr A Elbakry' \\ Ahmad Haffar (iD ${ }^{2}$ \\ Daniel McClelland' \\ Chad Morley (D)' \\ Osama Al-Omar (D) \\ 'West Virginia University Department of \\ Urology, Morgantown, WV, USA; ${ }^{2}$ West \\ Virginia University School of Medicine, \\ Morgantown, WV, USA
}

Background: The American Urological Association published guidelines in 2014 regarding management of undescended testicles (UDT). Despite these guidelines, prior studies have indicated discordance between guidelines and actual practice, especially in rural states. This study aims to identify if educating referring providers improves management of UDT.

Methods: Patients with UDT referred to our institution were divided into two groups: those referred prior to (Group 1) and after (Group 2) targeted education. A retrospective review was performed to compare the groups in terms of age at time of referral and surgery, laterality, specialty, and practice setting of referring provider, and whether or not ultrasound (US) was performed prior to referral.

Results: A total of 100 patients were identified in Group 1 and 168 in Group 2. No significant differences were noted between groups regarding age, variability of referring provider, or those receiving US prior to referral. Median age at referral was 20.7 months (range $=0-194$ ) and 33 months (range $=0-205.1$ ) in Groups 1 and 2, respectively $(p=0.26$ ). Sixty-two (37\%) patients underwent surgical evaluation within 18 months of age or younger in Group 1 compared to $39(39 \%)$ in Group $2(p=0.73)$. Private practice pediatricians comprised the majority of referring providers in both cohorts. US was performed prior to referral in $41 \%$ of patients in Group 1 compared to $35.8 \%$ in Group 2 ( $p=0.51$ ). The number of US ordered prior to referral significantly decreased from $10(50 \%)$ to six (19\%) following education among academic providers $(p=0.02)$. No significant difference was found following education for private practice physicians $(p=0.27)$.

Conclusion: Targeted education did not improve age at referral in the short-term, which may reflect suboptimal healthcare access. Additionally, more research is needed to evaluate whether more diverse targeted education provided on a regular basis to both physician and mid-level providers would have a meaningful impact.

Keywords: undescended testicle, guideline adherence, orchidopexy

\section{Introduction}

Cryptorchidism, or undescended testicle(s) (UDT), is the most common congenital anomaly in males with prevalence ranging from $1-3 \%$ and $15-30 \%$ in full-term and premature male infants, respectively. ${ }^{1}$ UDT places the male child at an increased risk for various health problems in the future, with the most notable being testicular cancer and subfertility. Children with UDT develop an increased risk of testicular cancer, with relative risk ranging from 2.5-8 when treatment is deferred to beyond 12 years of age, illustrating the importance of early detection and management. ${ }^{2,3}$
Correspondence: Tyler Trump

Tel + I 304-575-6976

Email ttrump@hsc.wvu.edu 
Additionally, there is an association between impaired fertility and delayed treatment of UDT with both clinical and histological measures of fertility superior in those who undergo treatment for UDT at an earlier age. ${ }^{4}$

The American Urological Association (AUA), recognizing the importance of timely identification and treatment of UDT, published in 2014 diagnostic and treatment guidelines for UDT. These guideline recommendations include referral of all children who fail to have spontaneous testicular descent by 6 months of age and surgical correction within 1 year (between 6 months and 18 months of age). The guidelines also recommend that physicians do not perform ultrasound (US) images as a part of their workup, as this rarely changes management due to this modality's low sensitivity in localizing a nonpalpable testis. ${ }^{5}$ It is also recommended to assess for testicular location in male children at all scheduled well-child appointments as a part of the physical exam, as $70 \%$ of all UDTs are palpable. ${ }^{5}$ This is concordant with the American Academy of Pediatrics (AAP) who recommend that a genital exam to assess the positioning of testicles be performed at every well child visit, as outlined in Bright Futures of the AAP. ${ }^{6}$

Given the guideline recommendations for UDT, reviewing the referral pattern and age at time of initial surgical consultation and treatment for UDT may serve as a quality-of-care indicator. Congruently, a publication from New Zealand suggested that age to orchidopexy could serve as a useful predictor of regional child health services. ${ }^{7}$ In our previously published study, we reviewed referral patterns to our tertiary referral institute, located in a rural state, between 2013 and 2014, and found that less than $50 \%$ of patients were referred and treated in accordance with AUA guidelines. ${ }^{8}$ A subsequent study comparing referral patterns between a rural tertiary care center and an urban referral center found no significant differences in the pattern of referral and treatment for UDT between a predominately rural academic center and an urban academic center. ${ }^{9}$

Given the discrepancies between the observed referrals and the guideline recommendations, there was concern that there remained an inconsistency in the familiarity with the guidelines between the referring physicians (pediatricians and family medicine physicians, etc.) and the pediatric urologists. The authors of this study believed that it may be beneficial to provide education regarding detection and referral of UDT to the primary care providers within the referral region. The purpose of this study is to compare the impact of targeted education to referring providers in a rural state based on the new guidelines from AUA, in particular the time of referral/surgery and US imaging. We hypothesized that there would be a significant difference in age at referral and subsequent surgery between patients referred before education and those referred after.

\section{Methods}

After obtaining appropriate approval from the institutional review board (IRB), a retrospective review was performed on all patients that underwent surgical exploration for UDT at our institution. Patients were identified by searching all Current Procedural Terminology (CPT) codes for surgical procedures listed as orchidopexy, laparoscopic orchidopexy, robotic orchidopexy, diagnostic laparoscopy, and orchiectomy. Patients who underwent these procedures for reasons other than UDT or who were referred for multiple complex urologic issues such as vesicoureteral reflux (VUR), hypospadias, penile abnormalities, and/ or bladder exstrophy were excluded.

We collected all patients meeting these criteria from between December 2012 and December 2017. December 2012 represents the starting date for our institution's pediatric urologist. Prior to this, our institution was without a board certified pediatric urologist for 3 years. A total of 268 patients were eligible for inclusion between December 2012 and December 2017. The targeted educational series regarding AUA guidelines started in December 2014. The patients were divided into two groups: those identified prior to December 2014 (preeducation, Group 1) and those identified during and after December 2014 (post-education, Group 2). The patients in Group 2 were then further sub-divided into three groups to account for lead time associated with permeation of the education: those referred within the first year (2015), second year (2016), and the third year (2017), from initiation of education.

Targeted education refers to series of lectures about the newly released AUA guidelines presented by the senior author to the pediatric and family medicine departments within our geographical referral catchment in the state and included: two major tertiary centers, community hospitals, the state annual conference of AAP, American College of Surgeons (ACS) WV chapter annual meeting, and major private groups. A total of eight grand rounds were given over 1 year. The lectures focused on the importance of regular genital examination, appropriate time to refer the 
patients, and appropriate diagnostic workup prior to referral. The prior findings in our previous study regarding referral patterns to our center were also presented and discussed. $^{8}$

Data collection included age at time of referral, laterality, palpability of the testicle as identified on exam under anesthesia, and referral-to-surgery time interval. The corrected gestational age at time of referral and surgery were calculated and compared. The characteristics of the referring provider were also identified as academic or private practice as well as their medical specialty. Information regarding specialty and type of practice was obtained from institutional website for the academic providers and from online review of licensing and board certification data for the private providers. We also identified if a scrotal ultrasound was performed prior to referral. Information regarding the US was obtained by reviewing our electronic medical records, reviewing all referral documentation, and asking the family if an US was performed prior to referral.

Statistical analysis was performed with significance defined as a $p$-value of equal to or less than 0.05. Mann Whitney $U$-test was used to compare the median age at time of referral between the pre- and post-education groups. Categorical variables were analyzed utilizing chisquared test while continuous variable means were compared utilizing independent sample $t$-test. ANOVA test was used to compare mean age at referral between the aforementioned sub-categories within the post-education group. All statistics were performed utilizing IBM SPSS statistic version 24. The study was conducted in accordance with the Declaration of Helsinki.

\section{Results}

A total of 100 patients and 168 patients with UDT underwent surgical exploration in Group 1 and Group 2, respectively. A total of 39 (39\%) patients underwent surgical intervention within the recommended period of 18 months of age in Group 1 compared to 62 (37\%) in Group 2, which was not statistically significant $(p=0.73)$. Median age was also assessed finding median age at time of referral of 20.7 (range $=0-194.7$ ) months and 33 (range $=0-205.1$ ) months in Groups 1 and 2, respectively $(p=0.26)$. Median time was analyzed between Group 1 and Group 2 regarding the interval between referral and surgery with a median of 140.5 (23-528 days) and 105 (51,756 days), respectively, which was found to be statistically significantly different $(p=0.01)$. Palpability of the UDT was compared between both groups and no statistical significance was found with the majority of referrals being for palpable testes $(p=0.67)$. Laterality was assessed and there was statistical significance noted in the distribution with more patients in Group 2 being referred for bilateral UDT $(p=0.01)$ (Table 1$)$.

Providers were divided based on the distinction of working in an academic versus private practice as well as based on their specialty. There were more referrals from private practice physicians than academic center physicians. Pediatricians represented the most common referring specialty. Sub-group analysis revealed that there was

Table I Demographic Data and Patients Characteristics

\begin{tabular}{|c|c|c|c|}
\hline & $\begin{array}{l}\text { Pre-Education (Group I), } \\
\qquad n=100\end{array}$ & $\begin{array}{c}\text { Post-Education (Group 2), } \\
n=168\end{array}$ & $p$-value \\
\hline Median age at referral (months) (range) & $20.7(0-194.7)$ & $33.0(0-205.1)$ & 0.26 \\
\hline$<18$ months at time of surgery, $n(\%)$ & $39(39)$ & $62(37)$ & \multirow[t]{2}{*}{0.73} \\
\hline$>18$ months at time of surgery, $n(\%)$ & $6 \mid(6 \mid)$ & $106(63)$ & \\
\hline $\begin{array}{l}\text { Median interval between referral and surgery Days } \\
\text { (range) }\end{array}$ & $140.5(23-528)$ & $105(5-1756)$ & $0.01 *$ \\
\hline Palpable testicle, $n$ (\%) & $56(56)$ & $104(61.9)$ & 0.67 \\
\hline Right side UDT, n (\%) & $59(59)$ & $71(42.3)$ & \multirow[t]{3}{*}{$0.01 *$} \\
\hline Left side UDT, n (\%) & $3 \mid(3 \mid)$ & $70(41.6)$ & \\
\hline Bilateral UDT, n (\%) & $10(10)$ & $27(16.1)$ & \\
\hline
\end{tabular}

Notes: *Statistically significant $p$-value. 
Table 2 Data on Referring Providers Broken Down into Subclass Based on Their Practice Setting and Specialty

\begin{tabular}{|c|c|c|c|}
\hline & Pre-Education (Group I) & Post-Education (Group 2) & $p$-value \\
\hline Total, n (\%) & $100(100)$ & $168(100)$ & \\
\hline \multicolumn{3}{|l|}{ Practice type } & \\
\hline Academic, n (\%) & $20(20)$ & $31(18)$ & \multirow{2}{*}{0.62} \\
\hline Mean age at referral & 30.2 months & 40.1 months & \\
\hline Private, n (\%) & $80(80)$ & $137(82)$ & \multirow[t]{2}{*}{0.73} \\
\hline Mean age at referral & 52.1 months & 51.8 months & \\
\hline \multicolumn{3}{|l|}{ Specialty } & \\
\hline Pediatrics, n (\%) & $81(8 I)$ & $134(80)$ & \multirow[t]{2}{*}{0.40} \\
\hline Mean age at referral & 45.6 months & 48.9 months & \\
\hline Family Medicine,n (\%) & $15(15)$ & $22(13)$ & \multirow[t]{2}{*}{0.44} \\
\hline Mean age at referral & 50.5 months & 57.5 months & \\
\hline Other, n (\%) & $4(4)$ & $12(7)$ & \multirow[t]{2}{*}{0.97} \\
\hline Mean age at referral & 78.4 months & 51.5 months & \\
\hline
\end{tabular}

no significant difference in average age of referral within these groups (Table 2).

There was no statistically significant difference in the total proportion of patients who received an ultrasound prior to referral between Group 1 and $2(p=0.27)$. Patients who received an US prior to evaluation were then stratified based on the practice type. There was no difference noted between Group 1 and 2 regarding US being performed following categorization based on practice type in the referrals from private providers $(p=0.16)$. In the sub-group of academic providers there were found to be statistically significantly less US performed in Group 2 when compared to Group $1(p=0.02)$. In Group 1 there were $44(44 \%)$ patients with a nonpalpable testicle compared to 64 (38\%) in Group 2. Of these, 23 (52\%) had an
US prior to referral in Group 1 compared to $19(30 \%)$ Group 2, which was statistically significant $(p=0.02)$. There were $10(10 \%)$ patients in Group 1 referred for bilateral UDT compared to $27(16.1 \%)$ in Group 2. Of the bilateral UDT referrals, four (40\%) underwent US prior to referral in Group 1 compared to eight $(29.6 \%)$ in Group 2 ( $p=0.55)$ (Table 3).

In Group 2 the patients were further sub-categorized into those referred within the first year, second year, and third year following initiation of the education series. ANOVA was then performed to assess if there was any difference between sub-groups in regard to age at time of referral and no statistical significance was found between these sub-groups $(p=0.14)$. Additionally, these subcategories were further analyzed to evaluate if there was

Table 3 Data on US Prior to Referral

\begin{tabular}{|c|c|c|c|c|}
\hline & & Pre-Education & Post-Education & \multirow[t]{3}{*}{$p$-value } \\
\hline & & Group I & Group 2 & \\
\hline & & Total, n (\%) & Total, n (\%) & \\
\hline \multirow[t]{6}{*}{ US performed prior to referral } & Total & $4 I(4 I)$ & $56(33)$ & 0.27 \\
\hline & Academic & $10(50)$ & $6(19)$ & $0.02 *$ \\
\hline & Private & $31(39)$ & $50(37)$ & 0.16 \\
\hline & Palpable Testicle & $18(32)$ & $37(36)$ & 0.66 \\
\hline & Non-palpable testicle & $23(52)$ & $19(30)$ & $0.02 *$ \\
\hline & Bilateral UDT & $4(40)$ & $8(29.6)$ & 0.55 \\
\hline
\end{tabular}

Note: *Statistically significant $p$-value. 
Table 4 Post-Education Cohort Stratified by Year of Referral Following Initiation of the Targeted Education

\begin{tabular}{|l|l|l|l|l|}
\hline & \multicolumn{1}{|c|}{ Year I } & \multicolumn{1}{|c|}{ Year 2 } & \multicolumn{1}{|c|}{ Year 3 } & \multirow{2}{*}{-value } \\
\cline { 2 - 4 } & \multicolumn{1}{|c|}{$\mathbf{n = 4 7}$} & \multicolumn{1}{|c|}{$\mathbf{n = 5 9}$} & \multicolumn{1}{|c|}{$\mathbf{n = 2}$} \\
\hline Mean age at referral & 45.3 months & 42.9 months & 59.4 months & 0.13 \\
US prior to referral, $\mathrm{n}(\%)$ & $13(28)$ & $22(37)$ & $21(34)$ & 0.42 \\
\hline
\end{tabular}

a difference regarding US being performed prior to referral. Chi-square analysis was used and no difference was noted $(p=0.42)$ (Table 4$)$.

\section{Discussion}

Initial data regarding the referral and treatment pattern for UDT from the Urologic Diseases in America Project in 2012 showed that the vast majority of patients undergoing surgical correction of their UDT during the appropriate time frame. ${ }^{10}$ Despite this early evidence, subsequent studies have demonstrated that the referral and treatment pattern for UDT is less than optimal with large percentages of patients undergoing surgical correction outside of the guideline recommended timeframe. ${ }^{8,9,11}$

One advantage of analyzing the referrals to our medical center is that the authors represent the only fellowship trained pediatric urologists within the state. Thus, the referral area is rather predictable and in theory representative of the state as a whole. The patient population served by our referral center notably has an increased percentage of patients with government-sponsored insurance. In 2016, $49 \%$ of WV children were insured through governmentassisted programs compared to the national average of $43 \%$. Median household income among our population is also decreased compared the national average with an average household income of $\$ 44,061 .^{12}$

The authors of this study demonstrated in a prior publication that only $21.4 \%$ of patients from a rural referral base underwent surgical correction for UDT between 6 and 12 months. $^{8}$ Given the well-described health disparities that exist among rural populations, these findings prompted interest in how rural referral pattern for UDT would compare to referral patterns at an urban center. A follow-up study comparing rural and urban referral patterns was conducted and among the two distinct populations there was no significant difference found in time of surgery, time of referral, time between referral and surgery, or patients who underwent evaluation with scrotal US prior to referral. ${ }^{9}$
Screening for UDT is common practice for pediatricians as the American Academy of Pediatrics recommends that a genital exam be performed at every well child check, as outlined by Bright Futures of the American Academy of Pediatrics. ${ }^{6}$ This recommendation is echoed by the AUA Guidelines. Given that the AUA guidelines were published only a few years prior to this data being collected, the authors of this study were hopeful that familiarization with the guidelines regarding UDT across the state and across the different referring specialties would improve the referral pattern with regard to timing of referral and diagnostic workup.

In the total study cohort, there were no significant differences found between the pre-education and posteducation population as regard to median age at referral or US ordered prior to referral, despite targeted education. A limitation of providing education in this manner is that the message may only be received by those who choose to attend. This can be particularly true regarding providers in private practice that may not attend society meetings. This was supported by our sub-analysis by stratifying the data according to practice type of referring providers. This subanalysis showed that there was no impact on the likelihood of ordering US after targeted education in private practice providers. On the other hand, providers in academic centers were more likely to change their practice and comply with the guidelines by avoiding US during their initial evaluation. These findings may indicate that targeted education may have a significant impact if it is successfully delivered to the targeted providers. This should include different specialties, as well as providers from different practice settings. One of the factors that may have played a role in limiting the effect of targeted education is the increasing number of the mid-level providers who practice in conjunction with other physicians. Expanding the targeted education process to include mid-level providers meetings and societies may improve its efficacy and subsequently increase the adherence to the guidelines.

The results of our current study did note an improved time interval between initial patient consultation and 
surgical intervention. This finding is believed to represent the senior author being allotted dedicated block time for cases as his practice was established. Prior to December 2012 our institution had been without a board certified pediatric urologist for more than 3 years. As a result, there was no protected block time for pediatric urology. As the senior author established his practice he was progressively granted block time in the operating rooms which allowed for more timely intervention.

Our results also showed a significant decrease in number of ordered US prior to referral in non-palpable testicles from $52 \%$ down to $30 \%$ after targeted education. However, we did not observe the same trend in palpable testicles. Ordering US, especially when the testicle is non-palpable, may be a reflection of seeking answers for the family and sometimes for the provider about the status of the testicle. This practice significantly decreased after targeted education for nonpalpable testicles. This is most likely due to multiple factors. One thought regarding this finding is the effect of high childhood obesity within our state making genital examination more difficult. For example, referring providers may order scrotal US for what appears to be a non-palpable testicle that in reality turns out to be a palpable testicle obscured by obesity. Unfortunately, full understanding of the magnitude of the effect of targeted education versus other factors is outside of the scope of this study.

The persistence of a delayed referral pattern despite education regarding the guidelines indicates that the reason for that delay is not only the lack of familiarity with the guidelines but also it can be a reflection of inadequate healthcare access and utilization, as echoed by other prior studies in various countries. ${ }^{7,13-16}$ UDT, being a largely asymptomatic condition, are likely only noticed by providers if regular maintenance screenings are performed or are found incidentally during appointments for other symptomatic complaints.

Based on these findings, it appears that adherence to best practice can be attributed to factors other than familiarity with guidelines and education by referring providers as educating providers regarding detection and treatment guidelines of UDT did not have an immediate impact on referral patterns and diagnostic workup. However, given the potential that patients with UDT are not being identified due to poor access to primary care, there is potential that providing education regarding best practice for UDT to parents prior to hospital discharge with their newborns may improve early detection of UDT and prompt further attention and evaluation. Unfortunately, this is above the scope of this study, but should be further investigated in future studies.

There are several limitations to the study including the retrospective nature of data collection. While targeted education was provided at several academic conferences, those impacted by the education were limited to those who chose to attend. Our data also did not provide specific information regarding the socioeconomic status of the patients, which could have an impact on the results based on the results of the Urologic Diseases of America 2012 dataset mentioned previously. Likewise, one limitation of this study is the focus on referrals leading to surgery, thus excluding referrals that did not prompt surgical intervention. This could have impacted the results as it might have been seen that there was an increase in non-operable referrals. For example, it is possible that targeted education increased awareness of UDT, which may lead to an increase in referrals for retractile testicles. These cases would not be captured in this study. Additionally, review of the referral records was especially limited when analyzing those referred from private groups. It remains uncertain whether our patients were regularly exposed to primary care prior to the visit that prompted the referral to pediatric urology. Further studies analyzing regularity of care among UDT patients would be paramount in identifying lack of primary care utilization as a driving force behind late referral to pediatric urology. We were also unable to reliably determine whether we were receiving a referral from a physician provider, a mid-level provider, or a combination. Mid-level providers in our state have the ability to practice independently and often do so, especially in more remote areas. This highlights the importance of providing the same resources to both physicians and mid-level providers. Finally, we cannot overlook the fact that over a 3-year period there will be turnover within the primary care community as well as a degree of education loss as the time from education increases. This point highlights the need for more regular education as well as education provided in different formats.

\section{Conclusion}

While there has been evidence to suggest that referrals for UDT are in congruence with guidelines in some areas, in rural areas referral, timely treatment and imaging during initial evaluation remains largely outside of the recommended guidelines. Our model of targeted education did not improve these metrics in the short-term, which may 
reflect that healthcare access and utilization is a large factor impacting adherence to the practice for UDT. Additionally, more research is needed to evaluate whether or not more diverse targeted education provided on a regular basis to both physician and mid-level providers would have a meaningful impact.

\section{Disclosure}

Dr Osama Al-Omar reports grants from Laborie Medical, outside the submitted work. The authors report no other conflicts of interest in this work.

\section{References}

1. Sijstermans K, Hack WW, Meijer RW, et al. The frequency of undescended testis from birth to adulthood: a review. Int $J$ Androl. 2008;31:1. doi:10.1111/j.1365-2605.2007.00770.x

2. Kokorowski PJ, Routh JC, Graham AD, Nelson CP. Variations in timing of surgery among boys who underwent orchiopexy for cryptorchidism. J Pediatr. 2010;126:576. doi:10.1542/peds.2010-0747

3. Barthold JS. Abnormalities of the testis and scrotum and their surgical management. In: Wein AJ, Kavoussi LR, Novick AC, editors. Campbell-Walsh Urology, 10th. Philadelphia: Elsevier Saunders; 2012:3696-3730.

4. Trsinar B, Muravec UR. Fertility potential after unilateral and bilateral orchidopexy for cryptorchidism. World J Urol. 2009;27:513. doi:10.1007/s00345-009-0406-0

5. Kolon TF, Herndon CD, Baker LA, et al. Evaluation and treatment of cryptorchidism: AUA guideline. $J$ Urol. 2014;192(2):337-345. doi:10.1016/j.juro.2014.05.005

6. Hagan JF, Shaw JS, Duncan PM, eds. Bright Futures: Guidelines for Health Supervision of Infants, Children, and Adolescents. 4th ed. Elk Grove Village, IL: American Academy of Pediatrics; 2017.
7. Bruijnen CJ, Vogels HD, Beasley SW. Age at orchidopexy as an indicator of the quality of regional child health services. $J$ Paediatr Child Health. 2012;48(7):556-559. doi:10.1111/j.14401754.2011.02202.x

8. DiBianco JM, Point D, Morley C, Zaslau S, Al-Omar O. The undescended testicles of West Virginia: a single center experience. West Virginia Med J. 2016;112(4):24-28.

9. Point D, Morley C, Tourchi A, et al. Rural versus urban compliance in the management of cryptorchidism: is there a difference? Eur J Pediatr. 2017;176(8):1067-1073. doi:10.1007/s00431-017-2946-4

10. Litwin MS, Saigal CS. Urologic Diseases in America. US Department of Health and Human Services. Public Health Service, National Institutes of Health, National Institute of Diabetes and Digestive and Kidney Diseases; 2012:97-160.

11. Jiang DD, Acevedo AM, Bayne A, Austin JC, Seideman CA. Factors associated with delay in undescended testis referral. J Pediatr Urol. 2019;15(4):380.e1-380.e6. doi:10.1016/j.jpurol.2019.03.029

12. US Census Data. "Statistics about the population of West Virginia." fast facts; 2018. Available from: dhhr.wv.gov/hpcd/data_reports/ pages/fast-facts.aspx. Accessed June 18, 2021.

13. Zvizdic Z, Islamovic B, Milisic E, Jonuzi A, Vranic S. Changing trends in the referral and timing of treatment for congenital cryptorchidism: a single-center experience from Bosnia and Herzegovina. $J \quad$ Pediatr Surg. 2020;55(9):1965-1968. doi:10.1016/j. jpedsurg.2019.08.013

14. Bergbrant S, Omling E, Björk J, Hagander L. Cryptorchidism in Sweden: a nationwide study of prevalence, operative management, and complications. J Pediatr. 2018;194:197-203.e6. doi:10.1016/j. jpeds.2017.09.062

15. Hidas G, Ben Chaim J, Udassin R, et al. Timing of orchidopexy for undescended testis in israel: a quality of care study. Isr Med Assoc J. 2016;18(11):697-700.

16. Boehme P, Geis B, Doerner J, Wirth S, Hensel KO. Shortcomings in the management of undescended testis: guideline intention vs reality and the underlying causes - insights from the biggest German cohort. BJU Int. 2018;122(4):644-653. doi:10.1111/bju.14171
Research and Reports in Urology

\section{Publish your work in this journal}

Research and Reports in Urology is an international, peer-reviewed, open access journal publishing original research, reports, editorials, reviews and commentaries on all aspects of adult and pediatric urology in the clinic and laboratory including the following topics: Pathology, pathophysiology of urological disease; Investigation and treatment of urological disease; Pharmacology of drugs used for the treatment of urological disease. The manuscript management system is completely online and includes a very quick and fair peer-review system, which is all easy to use. Visit http://www.dovepress.com/ testimonials.php to read real quotes from published authors. 